\title{
Surface energy exchange at the equilibrium line on the Greenland ice sheet during onset of melt
}

\author{
KONRAD STEFFEN \\ Cooperative Institute for Research in Environmental Sciences and Department of Geography, University of Colorado, \\ Boulder, CO 80309, U.S.A.
}

\begin{abstract}
The energy balance was measured at the ETH/CU research camp, located at the equilibrium-line altitude of the Greenland ice sheet $69^{\circ} 34^{\prime} \mathrm{N}$, $49^{\circ} 17^{\prime} \mathrm{W}$ ), in spring 1993. Prior to the onset of melt the latent energy flux is the only energy sink, with an average value of $1.18 \mathrm{MJ} \mathrm{m}^{-2} \mathrm{~d}^{-1}$. This turbulent transfer of moisture is responsible for an average daily snow sublimation of $5 \times 10^{4} \mathrm{~m}$. The sensible heat flux $\left(0.91 \mathrm{MJ} \mathrm{m}^{2} \mathrm{~d}^{1}\right)$ is the major energy source, and the net radiation only a minor contributor with a positive balance of $0.12 \mathrm{MJ} \mathrm{m}^{2} \mathrm{~d}^{1}$. The residual of the turbulent fluxes and the net radiation is about $0.14 \mathrm{MJ} \mathrm{m}^{-2} \mathrm{~d}^{-1}$, which agrees surprisingly well with the in situ ground-heat flux measurements of $0.15 \mathrm{MJ} \mathrm{m} \mathrm{J}^{-1}$ made at the same location. Assuming a $3{ }^{\circ} \mathrm{C}$ temperature increase in a global-change scenario, and using the information gained from the energy-balance measurements, a simple calculation showed that $5.4 \times 10^{2} \mathrm{~m}$ w.e. of snow would be lost by sublimation for an area of approximately $400000 \mathrm{~km}^{2}$. The increased sublimation is due to an increase in the net radiation balance caused by an albedo reduction. This would lead to a total annual mass reduction of $22 \mathrm{~km}^{3}$ w.e. of snow for the entire Greenland ice sheet, which is $4.2 \%$ of today's annual accumulation.
\end{abstract}

\section{INTRODUCTION}

The Greenland ice sheet plays an important role in the hemispheric circulation because of its topography and strong temperature gradient towards the northwestern Atlantic. The total area of Greenland is $2186000 \mathrm{~km}^{2}$, with the ice sheet covering an area of $1726000 \mathrm{~km}^{2}$ or approximately four-fifths of the island. In its central part, Greenland's ice sheet is $3000 \mathrm{~m}$ or more above sea level, and $1504200 \mathrm{~km}^{2}$ or $87 \%$ of the ice cap is above $1200 \mathrm{~m}$. The average slope of the ice sheet above the $1200 \mathrm{~m}$ elevation is about $0.4^{\circ}$.

The ice sheet plays an important role in the global climate system, particularly because of the amount of solar energy absorbed and reflected. The difference in albedo between dry snow $(\sim 0.85)$ and wet snow $(\sim 0.65)$ underscores the importance of the snow-melt conditions for energy exchanges with the atmosphere. Approximately $40 \%$ or $690000 \mathrm{~km}^{2}$ of the ice sheet was exposed to melt during the years 198891 (Abdalati and Steffen, in press).

The perturbation of the surface energy exchange of the Greenland ice sheet during a general global warming will now be estimated. Let us first assume a $3{ }^{\circ} \mathrm{C}$ airtemperature increase and an adiabatic lapse rate of $0.6^{\circ} \mathrm{C}$ per $100 \mathrm{~m}$, which seems reasonable for the Greenland ice sheet Orvig, 1970; Ohmura and others, 1991). This would result in a $500 \mathrm{~m}$ vertical rise of the $0^{\circ} \mathrm{C}$ isotherm during the summer's warmest period, with an approximately $80 \mathrm{~km}$ lateral shift of the wet-snow line, given an average $0.4^{\circ}$ slope of the ice sheet. In the months Mav September Konzelmann and others, 1994) a mean global radiation of $300 \mathrm{~W} \mathrm{~m}^{-2}$ can be assumed for the altitude band $1200-2000 \mathrm{~m}$, where surface melt occurs on the ice sheet. Given a perimeter of $5000 \mathrm{~km}$ and assuming an average width of $80 \mathrm{~km}$ of the wet-snow zone, the total area increase of the wet-snow zone above the equilibrium line would be approximately $400000 \mathrm{~km}^{2}$. Due to the albedo difference between wet and dry snow an additional $60 \mathrm{~W} \mathrm{~m}^{2}$ or roughly 24 terra watts would be absorbed by the ice-sheet surface. These assumptions are all rough generalizations and should serve only as a basis for discussion of the possible variation in the surface energy exchange with global warming.

\section{ENERGY EXCHANGE NEAR THE EQUILIBRIUM LINE}

A permanent research camp was established at the equilibrium-line altitude $(1155 \mathrm{~m}$ ) of the Greenland ice sheet $60 \mathrm{~km}$ northeast of Jakobshavn $69^{\circ} 34^{\prime} \mathrm{N}, 49^{\circ} 17^{\prime} \mathrm{W}$; see Fig. 1) in 1990 with the support of the Swiss Federal Institute of Technology, Zürich. Climatological measurements were carried out in order to study the energy exchange and the mass balance at the surface layer prior to and during the melt period. The station was taken over by the University of Colorado, Boulder, U.S.A., in 1992 in order to continue the field measurements. Observations of the surface energy balance are now presented for the 


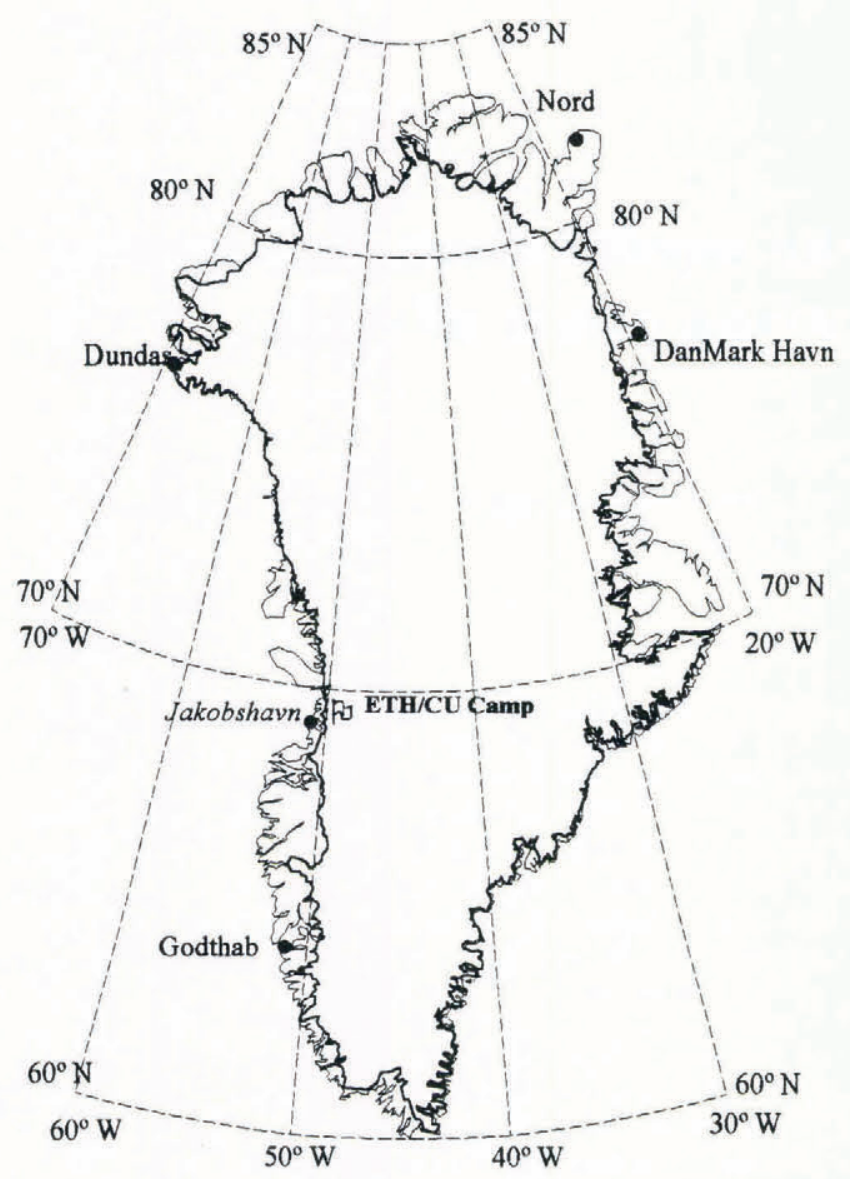

Fig. 1. Overview of the Greenland ice sheet. The outlines of the ice sheet and the land are shown. The location of the joint research camp of the Swiss Federal Institute of Technology, Zürich, and the University of Colorado, Boulder, U.S.A., is shown at the west side of the ice sheet near the village of Jakobshavn. pre-melt and melt periods. The energy balance is defined as follows:

$$
R_{\mathrm{n}}+Q_{\mathrm{H}}+Q_{\mathrm{E}}+Q_{\mathrm{M}}+Q_{\mathrm{G}}=0
$$

where $R_{\mathrm{n}}$ denotes the net radiation, $Q_{\mathrm{H}}$ the sensible heat flux, $Q_{\mathrm{E}}$ the latent heat flux, $Q_{\mathrm{G}}$ the sub-surface heat flux, and $Q_{\mathrm{M}}$ the energy used for melt. For convenience, all fluxes towards the surface are taken as positive.

The air temperature recorded at $2 \mathrm{~m}$ height (Fig. 2) shows a distinct diurnal cycle in spring with decreasing amplitude in late spring related to the decreasing solar zenith angle at midnight. The transition from winter to summer can clearly be seen in the abrupt rise of air temperatures from $-25^{\circ} \mathrm{C}$ to the freezing point. This warming can be explained by changes in the large-scale pressure distribution. The winter circulation is strongly dominated by two semi-permanent cyclones, the Baffin Bay low to the west and the larger Icelandic low to the southeast. The ice sheet is located under a weak saddle between the two depressions. The summer circulation is dominated by the pressure ridge extending from the northeast towards the center of the ice sheet. The largescale change in the circulation pattern is responsible for the abrupt temperature increase.

The energy fluxes will now be discussed for a $7 \mathrm{~d}$ period when air temperatures were just below the freezing point (see shaded area in Figure 2). Prior to that week, the surface had experienced some melting. The radiative fluxes were measured with two pyranometers, one pyrgeometer and one net radiometer (Table 1). Each parameter was measured at $1 \mathrm{~Hz}$ frequency and the average values were stored at $10 \mathrm{~min}$ intervals. The diurnal variations of the different radiation fluxes are shown in Figure 3 for the week-long period in May/June 1993. The global radiation peaked around solar noon with values around $750 \mathrm{~W} \mathrm{~m}^{-2}$ for clear sky, and around $650 \mathrm{~W} \mathrm{~m}^{-2}$ for overcast sky. At midnight the solar

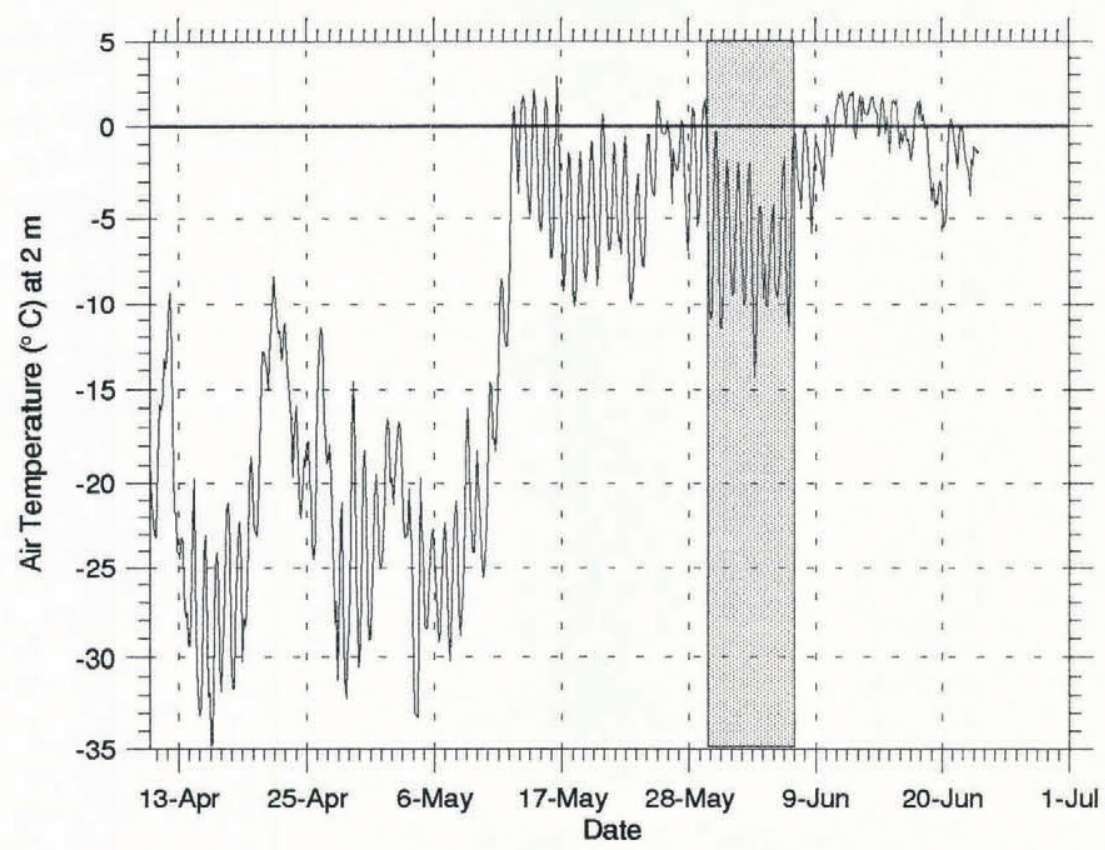

Fig. 2. Air temperature record $2 m$ above the ice surface at the ETH/CU research camp at the equilibrium-line altitude $(1155 \mathrm{~m})$ of the Greenland ice sheet, April/June 1993. 


\section{Parameter}

Instrument

Type

Precision

Heights

$\mathrm{m}$

Short-wave incoming radiation

Short-wave reflected radiation

Long-wave incoming radiation

Net radiation

Air-temperature profile

Humidity profile

Wind profile

Pressure

Temperature: eddy correlation method

Water-vapor flux: eddy correlation method

Wind-momentum flux: eddy correlation method

Snow temperature profile: ground-heat flux
Pyranometer

Pyranometer

Pyrgeometer

Single thermopile

Thermistor

Electric resistance

3 Cup anemometer

Barometric sensor

Fine wire thermocouple, $0.012 \mathrm{~mm}$ diameter

KH20 kryopton

hygrometer

Sonic anemometer

Thermocouple
Epply Precision

Pyranometer PSP

Epply Precision

Pyranometer (PSP)

Epply Precision

Rad. and Energy System

RH207 Fenwall

Electronics (UUT51J1)

RH207 Fenwall Electronics
Infrared Radiometer (PIR)
Met One Inc.

Setra SBP270

127 Campbell Scientific

Campbell Scientific

Campbell Scientific

Fluke, $80 \mathrm{PK}-2 \mathrm{~A}$

\begin{abstract}
(PCRC-11)
\end{abstract}
$\pm 1 \%$

$\pm 1 \%$

$\pm 2 \%$

$$
\pm 5 \%
$$

Error $\pm 0.4^{\circ} \mathrm{C}$ for $-33^{\circ}$ to $48^{\circ} \mathrm{C}$

Error $< \pm 5 \%$

Range: $12 \%-100 \%$

$$
\begin{aligned}
& \pm 1.5 \% \text { or } \\
& \pm 0.11 \mathrm{~m} \mathrm{~s}^{-1} \\
& \pm 0.2 \mathrm{mbar} \\
& \pm 0.016^{\circ} \mathrm{C}
\end{aligned}
$$

$0.54,1.04,2.1$

1.2

0.8

$$
< \pm \mathrm{g} \mathrm{m}^{3}
$$

$\pm 0.004 \mathrm{~ms}^{-1}$

$0.025,0.05$,
$0.54,1.04,2.1$

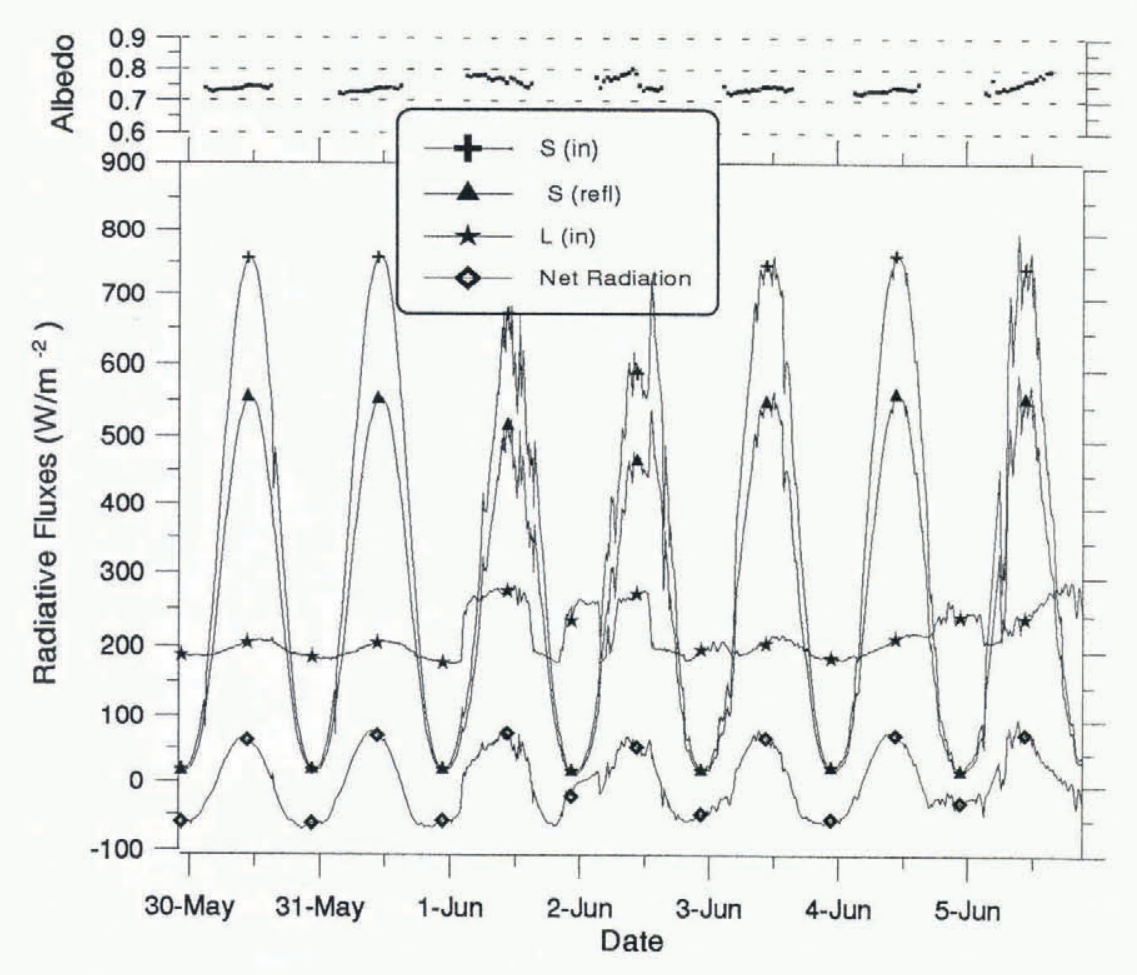

Fig. 3. Diurnal variation of short-wave incoming radiation $S$ (in), short-wave reflected radiation $S$ (refl), long-wave incoming radiation $L($ in $)$ and net radiation over a snow cover at the ETH/CU research camp, May/June 1993. Note the 5\% albedo change between clear and overcast sky (2 June 1993). 
radiation was still slightly positive $\left(50 \mathrm{~W} \mathrm{~m}^{-2}\right)$ with minimum solar zenith angles around $88^{\circ}$. The observed albedo under clear sky was 0.75 , and increased with overcast sky to 0.8 . The snow surface had experienced some prior melt, as mentioned above, but constant drift of dry snow from higher elevations (katabatic wind) increased the albedo from a typical wet-snow albedo, 0.65 , to 0.75 . Long-wave incoming radiation was $200 \mathrm{~W} \mathrm{~m}^{-2}$ under clear sky conditions and showed little diurnal variation. Under an overcast sky as on 1, 2 and 5 June the long-wave radiation increased by approximately $80 \mathrm{~W} \mathrm{~m}^{2}$. The net radiation showed a diurnal cycle with values around $-60 \mathrm{Wm}^{-2}$ at midnight and around $70 \mathrm{~W} \mathrm{~m}^{-2}$ at solar noon.

The latent and sensible energy fluxes were measured using both the aerodynamic (profile) method and the eddy fluctuation method. The instrumentation for the two different methods is given in Table 1. The latter method was based on a sonic anemometer and a kryptonabsorption hygrometer for measuring the turbulent fluxes at $10 \mathrm{~Hz}$. The sensible $(\mathrm{H})$ and the latent (LE) heat fluxes are given by:

$$
\begin{aligned}
\mathrm{H} & \equiv-\rho C_{\mathrm{p}} \overline{w^{\prime} \Theta^{\prime}} \\
\mathrm{LE} & \equiv-\rho L_{\mathrm{e}} \overline{w^{\prime} q^{\prime}}
\end{aligned}
$$

where $\rho$ denotes the density of air, $C_{\mathrm{p}}$ the specific heat of air, and $L_{\mathrm{e}}$ the latent heat of vaporization, and $w^{\prime}, \Theta^{\prime}$ and $q^{\prime}$ are the fluctuation parts of the vertical wind speed, temperature and humidity signal, respectively.

Results from the eddy fluctuation method are shown in Figure 4, covering the same time period as the radiative fluxes in Figure 3. The air temperature measured at $2 \mathrm{~m}$ was below freezing, approaching $0^{\circ} \mathrm{C}$ within $0.1^{\circ} \mathrm{C}$ at solar noon. The fluxes are plotted with the sign convention given in Equation (1). Net radiation is the primary energy source during the day and the major energy sink during the night when the Sun is low. On the average between 30 May and 5 June the net radiation was in surplus by $1.4 \mathrm{Wm}^{-2}$ (Fig. 5).

The latent heat (sublimation) was the major heat sink during the day. This is typical for the pre-melt time period on the Greenland ice sheet (Orvig, 1970). For lowSun angles the latent heat flux was slightly positive on a

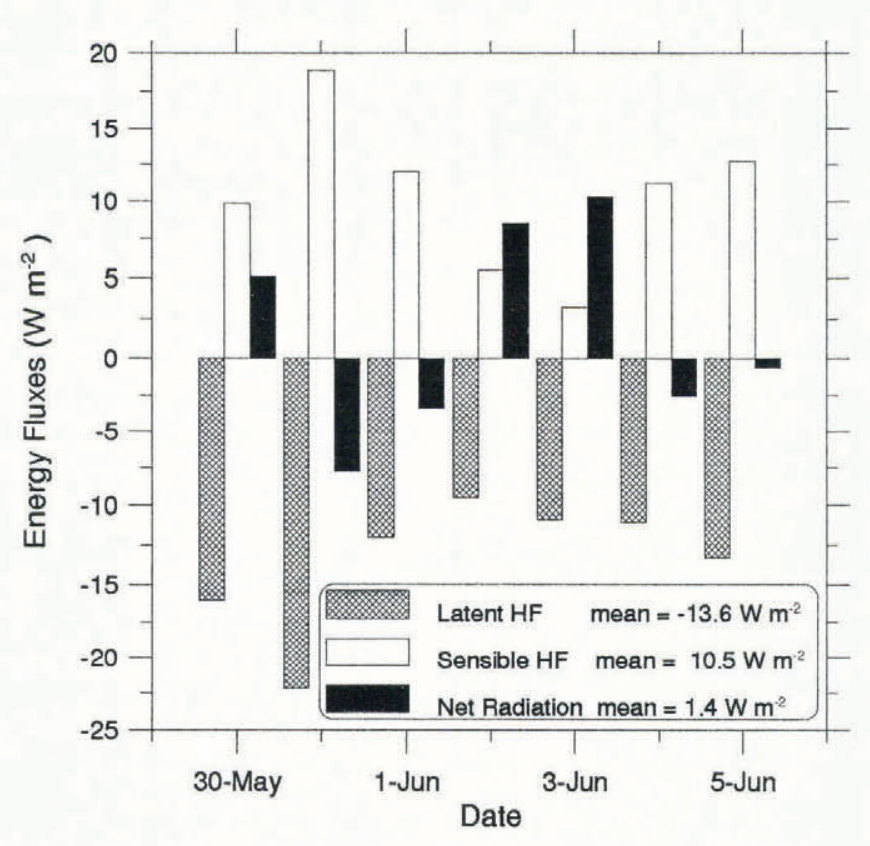

Fig. 5. Daily mean energy fluxes during pre-melt at the ETH $/ C U$ research camp on the Greenland ice sheet, May/ June 1993.

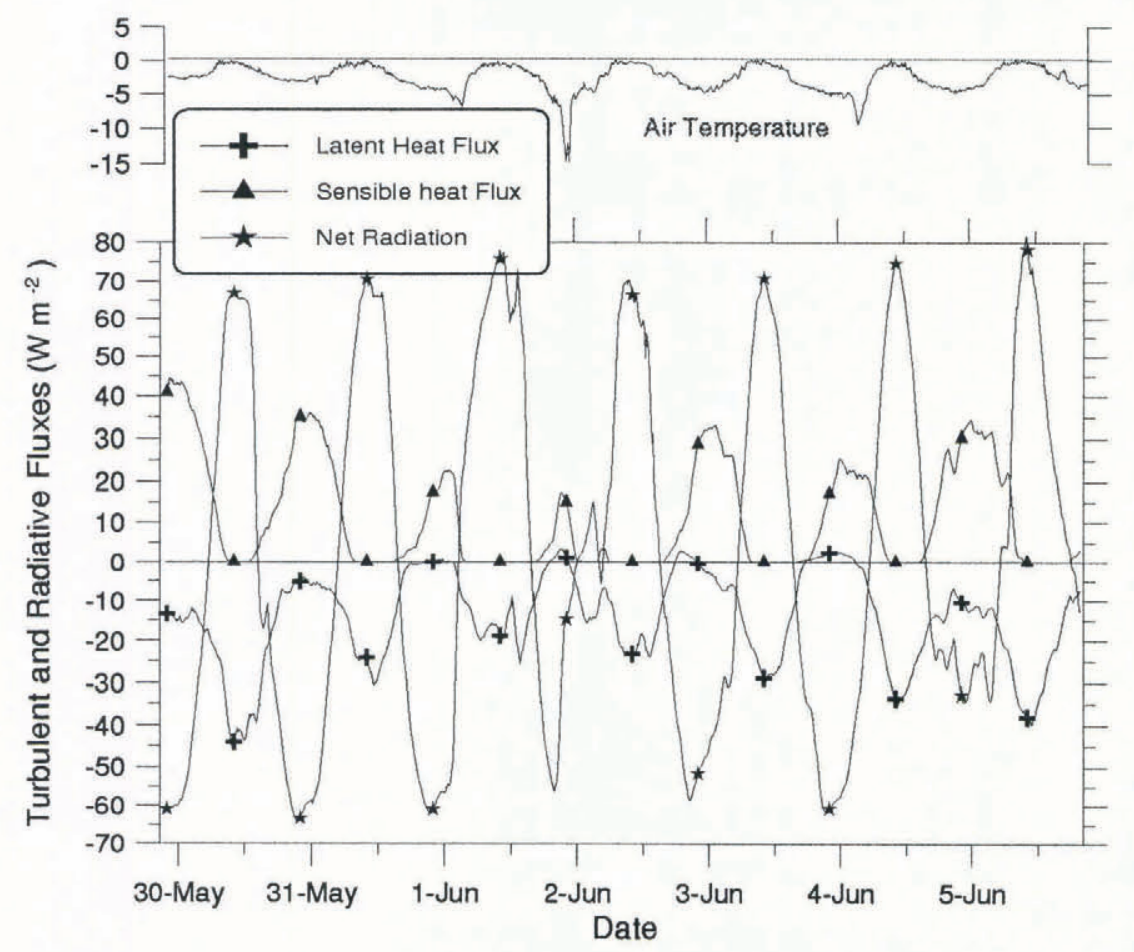

Fig. 4. Diurnal variation of turbulent and radiative energy fluxes over a snow surface. Throughout the time period 30 May5 . June 1993 the air temperature was below $0^{\circ} \mathrm{C}$, approaching freezing point within $0.1^{\circ} \mathrm{C}$ at solar noon. 
few occasions (condensation). On a daily average the flux was negative (Fig. 5). The average weekly energy used for the latent heat flux was $-13.6 \mathrm{Wm}^{-2}$, which equals an average sublimation rate of $4.1 \times 10^{-4} \mathrm{~m}$ water equivalent (w.e.) of snow per day. This is in agreement with snow ablation measurements made around the camp area at four different bamboo poles. For the time period 30 May-9 June a decrease in snow depth of $2 \mathrm{~cm}$ was recorded. Assuming a mean density of $250 \mathrm{~kg} \mathrm{~m}^{-3}$, as was measured for the top snow layer, the total sublimation rate would be $1.2 \mathrm{~cm}$ of snow for the $7 \mathrm{~d}$. The difference between the in situ measurements and the calculated sublimation could be explained by snow compaction. Apparently, the sublimation at the equilibrium-line altitude can be quite substantial, especially under föhn conditions, and the measurements at the ETH/CU camp compare well with weekly evaporation rates of $0.9 \mathrm{~cm}$ w.e. measured on the inland ice at $460 \mathrm{~m}$ elevation Orvig, 1970 ).

The sensible heat flux is positive during the night hours (energy flux into the snow) and counters in part the long-wave radiation loss (Fig. 4). During the day the vertical sensible flux does not exist since the air and snow-surface temperatures are both close to zero and the temperature gradient is too small for energy exchange. Therefore, the sensible heat flux is positive throughout the whole week (Fig. 5), and can be considered as the major energy source for sublimation. The weekly surplus of energy was calculated to be $10.5 \mathrm{Wm}^{-2}$, whereas the net radiation constituted a surplus of only $1.4 \mathrm{Wm}^{2}$.

The residual of the turbulent and radiation fluxes is the energy stored or released from the snow, $Q_{\mathrm{G}}$, the subsurface heat flux. Based on the flux measurements, $Q_{\mathrm{G}}$ was slightly positive at $1.7 \mathrm{Wm}^{-2}$. The ground-heat flux derived from temperature-profile measurements in the snow at four different levels is in good agreement with the residual of the eddy flux method. A mean flux of $1.6 \mathrm{Wm}^{2}$ was derived for the same week of 30 May-6 June at the ETH/CU research station (personal communication from W. Abdalati, 1994). I believe that this level of agreement is surprising, if not suspicious, considering the fact that energy-balance measurements are most difficult during the pre-melt period because the mean fluxes are small.

The turbulent energy fluxes were also measured using the aerodynamic method for the time period 26 May-22 June. During that time, dry-snow, onset-of-melt and melting-snow conditions occurred as can be inferred from the $2 \mathrm{~m}$ air-temperature recordings at the station (Fig. 2 ). It is not the aim of this paper to compare the aerodynamic and eddy correlation methods in detail. However, it is important to state that both methods gave very similar results for turbulent fluxes. The latent heat flux was approximately $20 \%$ smaller for the aerodynamic method compared to the eddy flux method, but both methods showed a maximum and minimum at the same times.

\section{ENERGY EXGHANGE DURING GLOBAL WARMING}

A striking question is how the energy exchange would be altered by a warmer climate. If we assume a $3{ }^{\circ} \mathrm{C}$ temperature increase, the wet-snow area of the Greenland ice sheet would increase by approximately $400000 \mathrm{~km}^{2}$, as mentioned earlier. The analyzed time period of observation at the ETH/CU camp was chosen to be representative for the described scenario. Prior to the time period investigated, there was some initial melt of the snow cover with temperatures above the freezing point, After this early melt, temperatures dropped again (Fig. 2). Therefore, a snow albedo of 0.75 might be quite typical for the regions that experience some initial melt. This is 0.1 lower than for the dry-snow regions of the ice sheet. Assuming a mean insolation of $300 \mathrm{Wm}^{-2}$ for the months May September Greuell and Konzelmann, 1994), an additional $30 \mathrm{Wm}^{2}$ would be available at the snow surface for the turbulent fluxes and the heating of the snow cover. In the case of increasing cloudiness, the global radiation would decrease and the surface albedo would increase, which has not been taken into account for this simple calculation. The energy-balance study at the ETH/CU camp during the pre-melt period showed that on average the energy surplus here is used for the sublimation of snow Fig. 5). Assuming a daily energy surplus of $2.59 \mathrm{MJ} \mathrm{m}^{2}$, this would lead to a daily sublimation rate of $9 \times 10^{4}$ mw.e., or $3.7 \times 10^{-3} \mathrm{~m}$ of snow with a density of $250 \mathrm{~kg} \mathrm{~m}^{3}$. If we assume that the additional melt areas occur in the middle of the summer and will last for approximately 2 months, a total of $0.22 \mathrm{~m}$ of snow would be sublimated within a year due to the albedo decrease. For the entire Greenland ice sheet, roughly $22 \mathrm{~km}^{3}$ w.e. of snow would be lost. Today, the mean annual accumulation on the Greenland ice sheet is estimated to be $520 \mathrm{~km}^{3}$ Ohmura and Reeh, 1991). Therefore, a $3^{\circ} \mathrm{C}$ airtemperature increase due to global warming would result in a $4.2 \%$ net loss of the annual accumulation due to sublimation. Over several years this could lead to a substantial mass-budget deficit if the accumulation remains at the present rate.

\section{CONGLUSIONS}

Energy flux measurements during the pre-melt period are extremely difficult because daily mean values of the sensible, the latent, the ground and the radiative fluxes are small. The diurnal variations for each flux are large and can vary considerably. However, the net radiation balance over a 1 week period is only $1.4 \mathrm{~W} \mathrm{~m}^{-2}$. On average, the sensible heat flux provides the net energy for the sublimation of the snow prior to the melt period. Heating of the snow cover was negligibly small for the period discussed (30 May-6 June). The ground-heat flux, derived as the residual from the other energy-balance components and from in situ measurements, had a slightly positive value (energy flux to the snow surface), which could be explained by the warm spell prior to the time period discussed in this paper.

In case of a global warming with increased air temperatures, the area of the wet-snow zone will increase significantly. Due to the reduced surface albedo with wet snow, there will be an additional $30 \mathrm{~W} \mathrm{~m}^{2}$ at the snow surface to dissipate. It is suggested that the excess energy 
from the net radiation will be used primarily for sublimation, which for a $3{ }^{\circ} \mathrm{C}$ warming will be approximately $22 \mathrm{~km}^{3}$ w.e. of snow on an annual basis. This is approximately $4.2 \%$ of the annual accumulation for the Greenland ice sheet.

\section{ACKNOWLEDGEMENTS}

This research was supported under grant NAGW-2158 by the NASA Polar Program, and by the Swiss National Foundation for Scientific Research grants 21-27449.89 and 20-36396.92. The author would like to acknowledge the field team of the $1993 \mathrm{ETH} / \mathrm{CU}$ Greenland expedition, namely J. Stroeve, W. Abdalati, M. Haefliger, and G. Niederbaeumer, and support with data analysis from E. Demaria.

\section{REFERENCES}

Abdalati, W. and K. Steffen. In press. Passive microwave-derived snow melt regions on the Greenland ice sheet, Geophysical Research Letters.

Greuell, W. and T. Konzelmann. 1994. Numerical modeling of the energy balance and the englacial temperature of the Greenland ice sheet. Calculations for the ETH-Camp location West Greenland, $1155 \mathrm{~m}$ a.s.l.) Global and Planetary Change, 9(1-2), 91-114.

Konzelmann, T., R.S. W. de Wal, W. Greuell, R. Bintanja, E. A. C, Henneken and A. Abe-Ouchi. 1994. Parameterization of global and long-wave incoming radiation for the Greenland ice sheet. Global and Planetary Change, 9 1-2), 143-164.

Ohmura, A. and N. Reeh. 1991. New precipitation and accumulation maps for Greenland. J. Glaciol., 37 (125), 140148.

Ohmura, A. and 8 others. 1991. Energy and mass balance during the melt season at the equilibrium line altitude, Greenland ice sheet. Progress report. Zürich, Eidgenössische Technische Hochschule. Department of Geography.

Orvig, S., ed. 1970. Climates of the polar regions. Amsterdam, etc., Elsevier. (World Survey of Climatology, Vol. 14. 